\title{
PEMANFAATAN TANAMAN OBAT SEBAGAI PENCEGAHAN PENYAKIT DEGENERATIF
}

\author{
UTILIZATION OF MEDICINAL PLANTS AS A PREVENTION \\ OF DEGENERATIVE DISEASE
}

\author{
${ }^{1)}$ Hasby, ${ }^{2)}$ Mauliza, ${ }^{3)}$ Mastura \\ 1,2,3 Program Studi Pendidikan Kimia, Universitas Samudra \\ Kampus Universitas Samudra, Meurandeh-Langsa \\ email: hasby@unsam.ac.id
}

\begin{abstract}
ABSTRAK
Pemanfaatan tanaman obat di pekarangan rumah untuk mencegah penyakit degenertif mampu meningkatkan taraf kesehatan masyarakat. Kegiatan pengabdian kepada masyarakat ini bertujuan untuk mengedukasi masyarakat dalam mengenal dan memanfaatkan tanaman obat sebagai pencegahan penyakit degeneneratif. Selain itu juga untuk mencegah dan menjadikan pertolongan pertama penyakit degeneratif agar tidak menjadi kronis dengan memanfaatkan tanaman obat. Kegiatan ini dilaksanakan di Desa Meurandeh Kecamatan Langsa Lama Kota Langsa, Aceh. Metode yang digunakan dalam kegiatan ini yaitu edukasi masyarakat melalui penyuluhan dengan memberikan penjelasan tentang penyakit degeneratif, melakukan sosialisasi jenis-jenis tanaman obat, manfaat dan aplikasinya. Kegiatan ini diikuti ibu-ibu rumah tangga anggota Pendidikan Kesejahteraan Keluarga (PKK), dan pemuda-pemudi yang ada di Desa Meurandeh. Hasil kegiatan menunjukkan masyarakat sangat antusias untuk mengenal, memanfaatkan secara langsung jenis-jenis tanaman obat dan mempraktikkan cara menanamnya pada media tanam. Pengetahuan dan pemahaman masyarakat Desa Meurandeh dalam mengenal, memanfaatkan, menanam/ membudidayakan, dan meracik sendiri tanaman obat sangat tinggi setelah kegiatan. Hal tersebut dapat dilihat berdasarkan pengolahan data dari angket yang disebar setelah kegiatan baik dari aspek kognitif, afektif, maupun konasi masyarakat peserta pelatihan.
\end{abstract}

Kata kunci : Edukasi, Penyakit Degeneratif, Tanaman Obat

\begin{abstract}
Utilization of medicinal plants in the home yard to prevent degenerative diseases can improve the level of public health. This community service activity aims to educate the public in recognizing and utilizing medicinal plants as the prevention of degenerative diseases. In addition, it is also to prevent and make first aid degenerative diseases so as not to become chronic by utilizing medicinal plants. This activity was held in Meurandeh Village, Langsa Lama Subdistrict, Langsa City, Aceh. The method used in this activity is public education through counseling by providing an explanation of degenerative diseases. Disseminating the types of medicinal plants, their benefits, and applications. This activity was attended by housewives, Family Welfare Education, and young people in Meurandeh Village. The results of the activity showed that the community was very enthusiastic to recognize, use directly the types of medicinal plants and practice how to plant them in the growing media. Knowledge and understanding of the people of Meurandeh Village in recognizing, utilizing, planting / cultivating, and concocting their own medicinal plants is very high after the activity. This can be seen based on the processing of data from the questionnaires distributed after the activities from the cognitive, effective, and community aspects of the training participants
\end{abstract}

Keywords: Education, Degenerative Diseases, Medicinal Plants 


\section{PENDAHULUAN}

Penyakit degeneratif merupakan penyakit tidak menular yang dapat berlangsung kronis/parah akibat penurunan fungsi organ tubuh akibat proses penuaan, seperti obesitas, penyakit jantung, diabetes, hipertensi, dan lainnya (Handajani, dkk., 2010). Beberapa jenis penyakit degeneratif berada pada peringkat 10 besar penyakit tidak menular yang menyebabkan masyarakat Indonesia harus menjalani rawat jalan atau rawat inap di beberapa rumah sakit maupun puskesmas.

Pemerintah Indonesia menetapkan kebijakan dalam upaya peningkatan pelayanan kesehatan untuk menanggulangi masalah penyakit degeneratif. Sistem Kesehatan Nasional adalah suatu tatanan yang menunjukkan upaya bangsa Indonesia untuk meningkatkan kemampuan taraf kesehatan yang optimal sebagai perwujudan kesejahteraan umum. Pemerintah juga menetapkan Keputusan Menteri Kesehatan RI No. 381/Menkes/SK/III/2007 dalam salah satu subsistem dari Sistem Kesehatan Nasional. Keputusan Menkes tersebut, menyebutkan bahwa pengembangan dan peningkatan penelitian uji klinis pemanfaatan obat tradisional ditujukan agar diperoleh obat tradisional yang bermutu tinggi, aman, memiliki khasiat nyata yang telah teruji secara ilmiah, dan dapat dimanfaatkan secara luas, baik digunakan untuk sendiri maupun dalam pelayanan kesehatan formal. Selain itu, pemerintah menetapkan Peraturan Menteri Kesehatan Nomor 9 Tahun 2016 tentang upaya pengembangan kesehatan melalui asuhan mandiri pemanfaatan tanaman obat keluarga dan keterampilan budidaya dan pengolahannya. Asuhan mandiri kesehatan tradisional adalah upaya untuk memelihara dan meningkatkan kesehatan serta mencegah dan mengatasi gangguan kesehatan ringan oleh individu, keluarga, kelompok, dan masyarakat dengan memanfaatkan tanaman obat keluarga dan keterampilan dalam memanfaatkannya. Tanaman obat atau yang dikenal dengan tanaman herbal secara umum dapat diartikan semua jenis tanaman yang mengandung senyawa kimia alami yang memiliki efek farmakologis dan bioaktivitas penting terhadap penyakit infeksi sampai penyakit degeneratif (Suryanto dan Setiawan, 2013).

Terletak di Kecamatan Langsa Lama, yang merupakan sentra pendidikan tinggi di Kota Langsa, Desa Meurandeh merupakan salah satu desa yang yang paling dekat dengan Universitas Samudra, dengan jarak $\pm 1 \mathrm{~km}$. Ternyata, berdasarkan data yang diperoleh dari bidan desa ada sekitar $22 \%$ penduduk yang menderita penyakit degeneratif dari keseluruhan jumlah masyarakat (1347 jiwa/September 2018) di Desa Meurandeh. Informasi lain yang diperoleh bahwa adanya penyakit degeneratif ini menjadi awal terjadinya komplikasi penyakit lainnya. Hasil wawancara dengan bidan desa juga didapatkan informasi bahwa, jika ada masyarakat mengalami keluhan adanya gejala penyakit degeneratif maka biasanya diberikan obat dokter. Hal ini menunjukkan bahwa masyarakat Desa Meurandeh langsung berobat ke bidan desa maupun puskesmas kecamatan Langsa Lama apabila sakit atau merasakan gejala penyakit degeneratif. Kesadaran akan pentingnya membudidayakan tanaman obat dan memanfaatkannya untuk mencegah penyakit degeneratif agar tidak menjadi kronis, belum tumbuh di masyarakat. Tujuan kegiatan pengabdian kepada masyarakat ini adalah untuk mengedukasi masyarakat dalam mengenal dan memanfaatkan tanaman obat sebagai pencegahan penyakit degeneneratif. Selain itu juga untuk mencegah dan menjadikan pertolongan pertama penyakit degeratif agar tidak menjadi kronis dengan memanfaatkan tanaman obat. 
Hasby, Mauliza, Mastura

Pemanfaatan Tanaman Obat Sebagai Pencegahan Penyakit Degeneratif

\section{METODE}

Kegiatan pengabdian kepada masyarakat ini dilakukan di Desa Meurandeh, Kecamatan Langsa Lama, Aceh. Kegiatan ini diikuti oleh 20 peserta yang terdiri dari ibu-ibu rumah tangga, PKK, dan pemuda-pemudi yang ada di Desa Meurandeh. Metode yang digunakan dalam kegiatan ini yaitu edukasi masyarakat melalui penyuluhan dengan cara transfer informasi dan pendampingan. Adapun rincian dari metode yang dilakukan adalah sebagai berikut.

a. Melakukan edukasi kepada masyarakat melalui metode ceramah/penyuluhan dengan memberikan penjelasan tentang penyakit degeneratif.

b. Melakukan sosialisasi jenis-jenis tanaman obat, manfaat dan aplikasinya. c. Mendistribusikan bibit tanaman obat yang siap untuk dibudidayakan sendiri oleh masyarakat.

d. Menanam/membudidayakan tanaman obat menggunakan media tanam memanfaatkan wadah-wadah sederhana dan tidak terpakai dalam rangka mengurangi biaya.

Metode dalam kegiatan pengabdian masyarakat ini didasarkan pada analisis situasi atas permasalahan mitra dan masyarakat sasaran, serta sumber daya yang ada di Desa Meurandeh. Kesepakatan bersama antara tim pengadian kepada masyarakat dan mitra dihasilkan beberapa solusi penyelesaian masalah dan output hasil kegiatan. Secara lebih jelas disajikan pada Gambar 1 dibawah ini.

\section{PERMASALAHAN DI DESA MEURANDEH}

a. Penduduk Desa Meurandeh menderita kolesterol, diabetes, asam urat, dan hipertensi

b. Kesadaran akan pentingnya membudidayakan tanaman obat dan memanfaatkannya untuk mencegah penyakit degeneratif agar tidak menjadi kronis, belum tumbuh di masyarakat.

c. Secara umum mereka mengetahui bahwa tanaman yang berada disekitarnya dapat menjadi pertolongan pertama untuk meringankan gejala penyakit degeneratif, namun tetap tidak berusaha membuat apotik hidup disekitar lingkungan rumah.

\section{JUSTIFIKASI SOLUSI YANG TELAH DISEPAKATI} BERSAMA

a. Melakukan edukasi kepada masyarakat melalui metode ceramah/penyuluhan dengan memberikan penjelasan tentang penyakit degeneratif.

b. Melakukan sosialisasi jenis-jenis tanaman obat, manfaat dan aplikasinya.

c. Mendistribusikan bibit tanaman obat yang siap untuk dibudidayakan sendiri oleh masyarakat.

d. membudidayakan tanaman obat menggunakan media tanam memanfaatkan wadah-wadah sederhana dan tidak terpakai dalam rangka mengurangi biaya

\section{SUMBER DAYA DI DESA MEURANDEH}

a. Ketersediaan bahan dan alat sederhana yang dibutuhkan dalam praktek bududaya tanaman obat.

b. Ketersediaan tempat untuk melakukan penyuluhan dan pelatihan.

\section{TUJUAN}

a. Mengedukasi masyarakat dalam mengenal dan memanfaatkan tanaman obat sebagai pencegahan penyakit degeneneratif pada masyarakat desa meurandeh

b. Mencegah dan menjadikan pertolongan pertama untuk penyakit degeratif pada masyarakat di Desa Meurandeh dengan memanfaatkan tanaman obat.

\section{OUTPUT}

a. Produk budidaya tanaman obat yang memiliki manfaat ekonomi dan kesehatan bagi masyarakat.

b. Pusat Tomas (Tanaman Obat Masyarakat)

Gambar 1. Bagan Kerangka Konsep Penyelesaian Masalah 
Selanjutnya dilakukan juga pengisian angket oleh peserta. Angket yang dibagikan berisi pertanyaan-pertanyaan untuk mengetahui ketercapaian tujuan kegiatan ini. Angket ini untuk melihat aspek kognitif, afektif dan konasi masyarakat peserta pasca kegiatan.

\section{HASIL DAN PEMBAHASAN}

\section{Penyuluhan Penyakit Degeneratif dan Sosialisasi Tanaman Obat sebagai Pencegahannya.}

Kegiatan penyuluhan tentang penyakit degeneratif dan sosialisasi tanaman obat sebagai pengobatan dan upaya pencegahannya dilakukan di kantor Geuchik (kepala desa) Desa Meurandeh. Peserta yang hadir dalam kegiatan tahapan pertama ini sebanyak 20 orang. Diharapkan ibu-ibu yang hadir dalam kegiatan dapat membagikan informasi kepada masyarakat lainnya disekitarnya. Pada kegiatan penyuluhan tentang penyakit degeneratif ini dijelaskan difinisi dan berbagai penyakit yang termasuk penyakit degeneratif. Berbagai cara yang dapat dilakukan masyarakat untuk mencegah dan mengobati penyakit ini juga telah dijelaskan, diantaranya mengenali penyebabnya dan gejala-gejala yang mengikutinya. Dari kegiatan tanya jawab, masyarakat mengeluhkan efek samping dari penggunaan obat dokter. Konsumsi obat dokter untuk pencegahan penyakit degeneratif menyebabkan ketergantungan dan yang paling banyak dikeluhkan oleh peserta adalah menurunya fungsi pendengaran akibat terlalu sering minum obar dokter. Oleh karena itu tim pelaksana mengedukasi masyarakat untuk menggunakan tanaman obat yang alami, sebagai pengobatan dan pencegahan penyakit degeneratif.

Pada kegiatan sosialisasi tanaman obat untuk pencegahan penyakit degeneratif dikenalkan 20 jenis tanaman. Tanaman yang dikenalkan antara lain Belimbing Manis, Binahong, Kelor,
Kembang Pukul Empat, Kenikir, Kumis Kucing, Lidah Buaya, Mimba, Murbei, Pacar Air, Pegagan, Salam, Salam Koja, Sambiloto, Sambung Nyawa, Seledri, Sirih Merah, Sirsak, Tapak Dara, dan Temulawak. Untuk mempermudah sosialisasi tanaman obat kepada masyarakat tim juga menggunakan katalog dari 20 jenis tanaman obat, yang juga merupakan produk bermanfaat dari kegiatan ini. katalog ini berisi nama tanaman (nama ilmiah, daerah, dan asing), kandungan kimia dan efek farmakologis, serta bagian yang digunakan dan pemanfaatannya.. Masyarakat yang umumnya merupakan ibu rumah tangga sangat antusias dengan dua manfaat tanaman-tanaman ini. Banyaknya pertanyaan yang diajukan peserta saat sesi tanya jawab menunjukkan respon yang sangat positif. Masyarakat baru mengetahui bahwa bahwa tanaman yang selama ini juga ada disekitar mereka sebagai tanaman semak merupakan tanaman obat.

Pembagian bibit, menanam/budidaya tanaman obat, dan pemberian name tag untuk setiap tanaman.

Kegiatan pembagian bibit dan pelatihan budidaya tanaman obat dilaksanakan di halaman kantor Desa Meurandeh. Jumlah yang hadir dalam kegiatan tahapan kedua ini sebanyak 20 orang. Beberapa bibit dan anakan tanaman yang dibagikan kepada masyarakat antara lain Belimbing Manis, Binahong, Kelor, Kembang Pukul Empat, Kenikir, Kumis Kucing, Lidah Buaya, Murbei, Pacar Air, Pegagan, Salam, Salam Koja, Sambiloto, Seledri, Sirih Merah, Sirsak, Tapak Dara Putih, dan Temulawak. Beberapa jenis tanaman obat yang dimanfaatkan oleh masyarakat Indonesia, antara lain: kunyit, temu lawak, kencur, jahe, lengkuas, salam, kumis kucing, soka, belimbing, sirih, meniran, kecubung, kemlandingan, kangkung lumut, pegagan, dan tapak dara 
Hasby, Mauliza, Mastura

Pemanfaatan Tanaman Obat Sebagai Pencegahan Penyakit Degeneratif

putih (Syarif, dkk., 2011). Hasil penelitian Fitriyah, dkk., (2013) membuktikan bahwa tanaman binahong (Anredera cordifolia) adalah tanaman obat yang sangat berpotensi mengatasi berbagai jenis penyakit, termasuk penyakit degeneratif. Bagian tanaman binahong yang bermanfaat sebagai digunakan sebagai obat pada umumnya adalah daun.

Setelah bibit dibagikan, maka dilakukan kegiatan pelatihan cara menanam tanaman obat yang meliputi praktek pembuatan media tanam, menyemai bibit pada media tanam, cara merawat media tanam, dan praktek memindahkan bibit tanaman obat ke dalam pot. Tim pengabdian mencontohkan dan mengarahkan peserta kegiatan untuk mempraktekkan sendiri menanam tanaman obat. Peserta memberikan respon yang sangat positif yang terlihat dari partisipasi aktif semua peserta mencoba langsung menanam pada media tanam. Setelah tanaman selesai dipindakan ke dalam media tanamnya, selanjutnya peserta memberikan tag name pada masing-masing tanaman. Setengah dari tanaman yang diberikan tag name ditempatkan di halaman kantor Desa Meurandeh. Hal ini bertujuan untuk menjadikan halaman kantor desa sebagai salah satu pusat tanaman obat masyarakat (Tomas), dan juga pengenalan jenis-jenis tanaman obat kepada seluruh masyarakat yang sedang berkunjung ke kantor Desa Meurandeh. Sementara itu, setengah dari tanaman yang didistribusikan dibagikan kepada ibu-ibu peserta kegiatan.

Setelah kegiatan selesai dilakukan, setiap peserta kegiatan diminta mengisi angket untuk melihat aspek kognitif, afektif, dan konasi peserta setelah kegiatan. Hal ini bertujuan untuk melihat tingkat pencapaian tujuan dari program pengabdian masyarakat di Desa Meurandeh setelah kegiatan dilakukan. Aspek kognisi, afeksi dan konasi peserta pelatihan secara lebih rinci adalah sebagai berikut :

Hasil yang didapatkan

menunjukkan bahwa, pengetahuan peserta mengenai jenis-jenis dan manfaat tanaman obat sangat tinggi (100\%). Sementara itu, pengetahuan untuk menanam, membudidayakan, dan meracik tanaman obat sebagai pencegahan penyakit degeneratif juga sangat tinggi (90\%).

Hal ini menunjukkan bahwa kegiatan ini memberikan dampak yang positif kepada masyarakat Desa Merandeh dari aspek kognitif. Kesadaran masyarakat lokal atau masyarakat desa untuk mengenal dan manfaatkan sumber daya tumbuhan akan sangat membantu menjaga kelestarian keanekaragaman hayati dan usaha domestikasi tanaman obat (Kandari, dkk, 2012).

Pada aspek afeksi peserta kegiatan hasil yang didapatkan menunjukkan bahwa, rasa ingin tahu peserta mengenai jenis-jenis sangat tinggi (100\%). Sementara itu, $90 \%$ peserta akan memanfaatkan, menanam dan membudidayakan tanaman obat sebagai upaya pencegahan penyakit degeneratif dirumah. Hasil pengolahan angket juga menunjukkan bahwa $80 \%$ peserta yang telah mengikuti kegiatan akan meracik tanaman obat sebagai pencegahan penyakit degeneratif. Hal ini juga menunjukkan bahwa kegiatan ini memberikan dampak yang positif kepada masyarakat Desa Merandeh dari aspek afeksi.

Konasi merupakan predisposisi tindakan seseorang terhadap suatu aspek di lungkungan sekitarnya (Azwar, 2015). Hasil yang didapatkan menunjukkan bahwa, $100 \%$ peserta akan terus menambah wawasan mengenai jenis-jenis tanaman obat sangat tinggi (100\%). Sementara itu, $90 \%$ peserta akan terus memanfaakan tanaman obat sebagai upaya pencegahan penyakit degeneratif dirumah. Hasil pengolahan angket juga menunjukkan bahwa $80 \%$ peserta yang telah mengikuti kegiatan akan menanam, membudidayakan, dan meracik tanaman obat sebagai pencegahan penyakit 
degeneratif. Hal ini juga menunjukkan bahwa kegiatan ini memberikan dampak yang positif kepada masyarakat Desa Merandeh dari aspek konasi. Hal tersebut tentunya dapat menjadikan masyarakat sadar bahwa tanaman obat adalah pilihan yang tepat sebagai pengobatan alami untuk mencegah penyakit degeneratif. Inilah yang melatarbelakangi bahwa alternatif pengobatan alami menawarkan biaya pengobatan yang lebih terjangkau daripada pengobatan modern, serta tidak adanya efek samping jangka panjang yang berbahaya untuk organ lain dalam tubuh (Effendi, 2013).

Selanjutnya dilakukan peninjauan kembali untuk melihat perawatan tanaman obat yang ada di halaman kantor desa Meurandeh sebagai evaluasi pelaksanaan kegiatan. Hasil peninjauan menujukan hal yang positif diamana terlihat tanamantanaman tersebut terawat dan tumbuh dengan subur. Hasil kegiatan ini terlihat peran masyarakat sangat penting dalam merawat dan membudidayakan tanaman obat yang dibagikan. Peran serta masyarakat dalam membantu peningkatan taraf kesehatan berdasarkan Primary Health Care $(P H C)$ adalah berupa pengelolaan pengobatan tradisional (Badan Pusat Statistik, 2008).

\section{UCAPAN TERIMA KASIH}

Penulis mengucapkan terima kasih kepada LPPM dan PM Universitas Samudra, Kota Langsa, Aceh yang telah memfasilitasi kegiatan ini. Kepala desa, jajaran, dan seluruh masyarakat Desa Meurandeh, Kec Langsa Lama, Kota Langsa, Aceh yang telah terlibat dalam kegiatan ini. Mahasiswa yang ikut membantu seluruh kegiatan ini.

\section{SIMPULAN}

Pemahaman awal masyarakat mengenai beberapa jenis-jenis dan manfaat tanaman obat masih terbatas. Hasil kegiatan menunjukkan masyarakat sangat antusias untuk mengenal, memanfaatkan, menanam secara langsung jenis-jenis tanaman obat dan mempraktikkan cara menanamnya pada media tanam. Pengetahuan dan pemahaman masyarakat Desa Meurandeh dalam mengenal, memanfaatkan, menanam/ membudidayakan, dan meracik sendiri tanaman obat sangat tinggi setelah kegiatan. Hal tersebut dapat dilihat berdasarkan pengolahan data dari angket yang disebar setelah kegiatan baik dari aspek kognitif, afektif, maupun konasi masyarakat peserta pelatihan.

\section{DAFTAR PUSTAKA}

Azwar, S, (2015). Sikap Manusia Teori dan Pengukurannya. Yogyakarta: Pustaka Pelajar.

Badan Pusat Statistik-Statistics Indonesia (BPS). (2008). National Family Planning Coordinating Board, Ministry of Health, ORC Macro. Indonesia Demographic and Health Survey 2007. Indonesia: Badan Pusat Statistik-Statistics Indonesia.

Effendi, M. (2013). Pemanfaatan Sistem Pengobatan Tradisional (Battra) di Puskesmas. Surabaya: FISP-UNAIR.

Fitriyah, N., Purwa, M.K., Alfiyanto, A.M., Mulyadi., Wahuningsih, N., dan Kismanto, J. (2013). Obat Herbal Antibakteri Ala Tanaman Binahong. Jurnal KesMaDaSka. 1 (1), 116-122.

Handajani, A., Roosihermatie, B,. Maryani, H. (2010). Faktor-Faktor yang Berhubungan dengan Pola Kematian Pada Penyakit Degeneratif di Indonesia. Buletin Penelitian Sistem Kesehatan, 13 (1). 42-53.

Kandari, L.S., Phondani, P.C., Payal, K.C., Rao, K.S. dan Maikhuri, R.K. (2012). Etnobotani Study toward Conservation of Medicinal and Aromatic Plant in Upper Catchments of Dhauli Ganga in the Central Himalaya. Jurnal of Mountain Science, 9 (1), 286-296. 
Kementerian Kesehatan. (2016). Peraturan Menteri Kesehatan Nomor 9 Tahun 2016. Jakarta: Kementerian Kesehatan.

Keputusan Menteri Kesehatan (2007). Keputusan Menteri Kesehatan RI No. 381/Menkes/SK/III/2007. Jakarta: Keputusan Menteri Kesehatan.

Suryanto, R dan Setiawan, D. (2013). Struktur Data Datawarehouse Tanaman Obat Indonesia dan Hasil Penelitian Obat Tradisional (Seminar Nasional Sistem Informasi Indonesia). Jurnal Ilimiah Farmasi-UNSRAT , 5 (2), 2302-2493.

Syarif, P., Suryotomo, B., dan Soeprapto, H. (2011). Diskripsi dan Manfaat Tanaman Obat di Pedesaan, Sebagai Upaya Pemberdayaan Apotik Hidup (Studi Kasus di Kecamatan Wonokerto). Pena Jurnal Ilmu Pengetahuan dan Teknologi, 21 (1), 20-32 